\title{
Testing the Force Absorption of Composite Materials to Select the Best for Making a Helmet
}

\author{
Božo Bujanić, Matija Košak*
}

Abstract: The paper presents and describes the procedure of testing the materials that were available for the production of a multifunctional protective helmet. The procedure was carried out at the company Šestan-Busch d.o.o. as part of the EU project for the development and production of a multifunctional protective helmet. The test results showed that carbon fibers polymers as a composite material have the best impact absorption properties which was a key criterion for material selection. Other materials; glass fibers polymers, aramid fibers polymers and combinations in the test procedure showed worse results compared to the selected criterion.

Keywords: aramid fibers; carbon fibers; composite materials; glass fibers; impact absorption; multifunctional protective helmet

\section{INTRODUCTION}

The project of a multifunctional protective helmet (Fig. 1) was realized through the phases of design and development, procurement of specific equipment and realization i.e. serial production.

In the development and design phase, all the necessary input parameters were collected, i.e. data and information in order to be able to approach the development of a multifunctional safety helmet.

One of the requirements was that the helmet has the best possible protective properties against mechanical impacts and that it should be as light as possible, which required the selection of adequate materials for its production. The designers had at their disposal composite materials used to make protective helmets. Specifically, these were polymers with carbon fiber, glass fiber, aramid fiber, and a combination of aramid and carbon fiber [1].

These composite materials are characterized by high strength and low mass [2,3]. Higher strength means that the material absorbs a large part of the impact force, which means that a smaller part of the impact force will be transferred to the head of the user using the helmet.

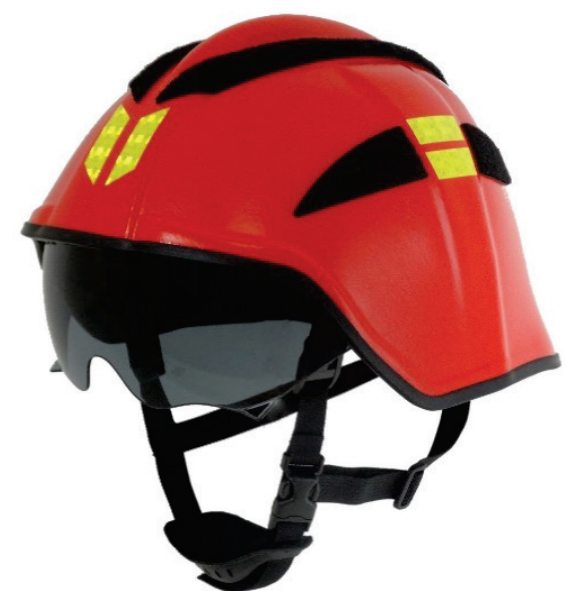

Figure 1 Multifunctional safety helmet [4]

\section{TEST OF IMPACT RESISTANCE OF MATERIALS}

The test was performed on a Hototech machine, shown in Fig. 2. The hototech machine is the machine with the special purpose of helmet impact testing but it can be used in different ways as well.
The machine has the ability to release weights of a certain mass by free fall on the object under test, and is equipped with adequate software.

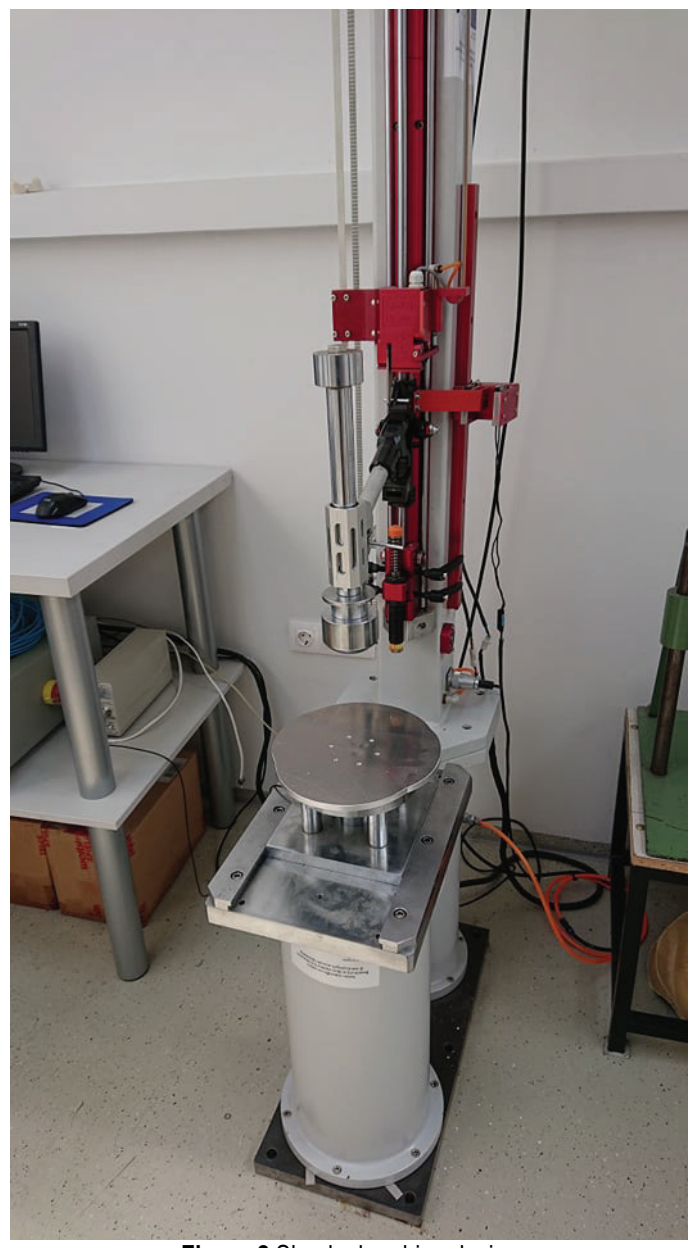

Figure 2 Shock absorbing device

\subsection{Sample Preparation}

Specimens prepared for the experiment were in the tile shape with dimensions $150 \times 120 \times 2 \mathrm{~mm}$. Four types of specimens were prepared, tiles with carbon fibers reinforcement, aramid fibers, glass fibers and with the 
combination carbon-aramid (2 layers of aramid fibers and 5 layers of carbon fibers). The tiles are shown in Fig. 3. From each of the listed materials, 6 tiles were made. Each tile consists of 7 layers of composite fibers. The tiles are made by manual lamination with epoxy resin matrix. By the procedure described in the book Comprehensive composite materials [5].

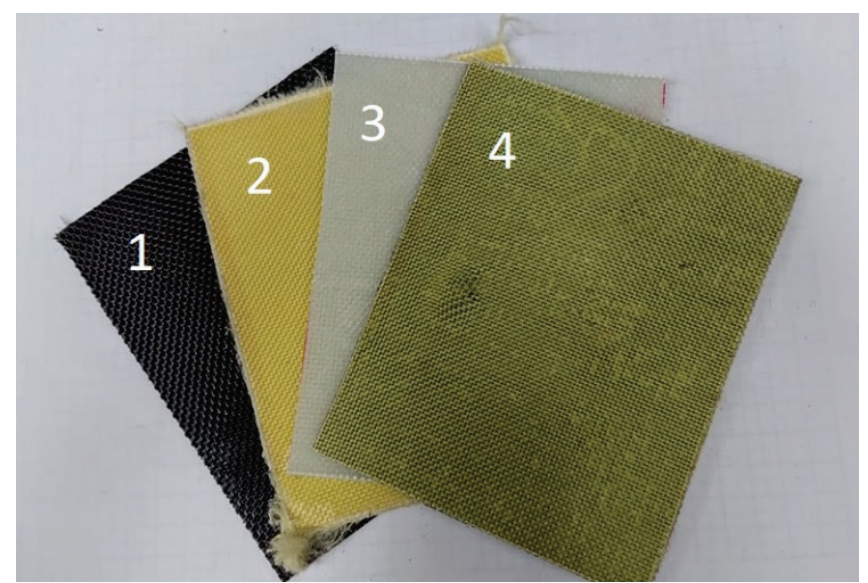

Figure 3 Sample tiles of composite materials; 1 - carbon fiber, 2 - aramid fiber, 3 glass fiber, 4 - combination of aramid and carbon fiber

After preparing samples of composite materials, samples of PE foam were also prepared. The material of the foam is polyethylene because the pads in the interior of the protective helmet are made of the same material [6].

Foams measuring $125 \times 155 \times 10 \mathrm{~mm}$ and a foams measuring $125 \times 155 \times 20 \mathrm{~mm}$ were made for the two work cycles of the test.

\subsection{Test Procedure}

The test was conducted in three cycles, specifically;

- $\quad 1^{\text {st }}$ test cycle of tiles without foam base,

- $\quad 2^{\text {nd }}$ test cycle with a $10 \mathrm{~mm}$ thick foam base,

- $3^{\text {rd }}$ test cycle with a $20 \mathrm{~mm}$ thick foam base.
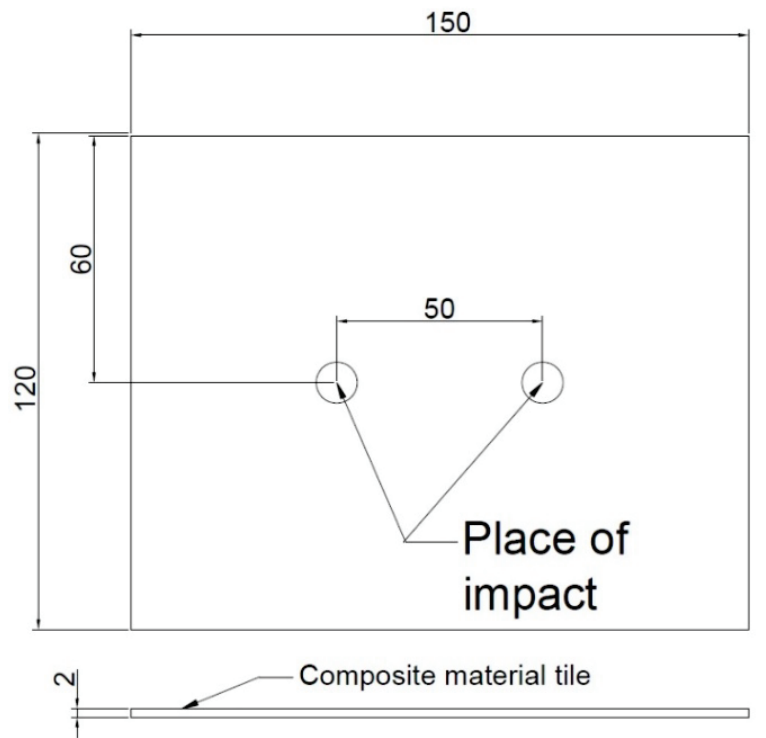

Figure 4 Drawing of the tile and the place of impact
The test cycles were carried out in such a way that a weight of $5 \mathrm{~kg}$ was released from the Hototech device from a height of one meter, and the residual force after impact on the sample was measured by means of a sensor. Two specimen of each material were tested in each of the cycles. In each cycle, the specimens were tested twice at precisely defined places (Fig. 4).

In addition to measuring the force on the device, the speed at certain heights of weights was also measured. After the test procedure the results could be compared and adequate conclusions could be drawn.

The first part of the tiles was tested without a foam which additionally absorbs the impact. In the second and third cycles, a foam $10 \mathrm{~mm}$ and $20 \mathrm{~mm}$ thick was placed under the tiles. After each impact, the force sensor measure the remaining amount of force that the material failed to absorb.

\section{RESULTS AND DISCUSSION 3.1 Test Results}

The results of the first cycle in which the tiles were tested without the foam are shown in Tab. 1. The values given in Tab. 1 show the force measured on the force sensor.

\begin{tabular}{|c|c|c|c|c|c|}
\hline \multirow[b]{2}{*}{ Sample } & \multirow[b]{2}{*}{ Strike } & \multicolumn{4}{|c|}{ Measured force $(\mathrm{kN})$} \\
\hline & & $\begin{array}{l}\text { Glass } \\
\text { fibers }\end{array}$ & $\begin{array}{c}\text { Carbon } \\
\text { fiber }\end{array}$ & $\begin{array}{l}\text { Aramid } \\
\text { fibers }\end{array}$ & $\begin{array}{l}\text { A combination } \\
\text { of carbon and } \\
\text { aramid fibers }\end{array}$ \\
\hline \multirow{2}{*}{$\begin{array}{c}1^{\text {st }} \\
\text { sample }\end{array}$} & I & 21.63 & 21.02 & 21.59 & 21.29 \\
\hline & II & 22.27 & 21.43 & 21.59 & 21.55 \\
\hline \multirow{2}{*}{$\begin{array}{c}2^{\text {nd }} \\
\text { sample }\end{array}$} & III & 22.13 & 21.42 & 21.61 & 21.63 \\
\hline & IV & 21.96 & 21.15 & 21.35 & 21.41 \\
\hline \multicolumn{2}{|c|}{ Arithmetic mean $(\bar{X})$} & 21.99 & 21.25 & 21.53 & 21.47 \\
\hline
\end{tabular}

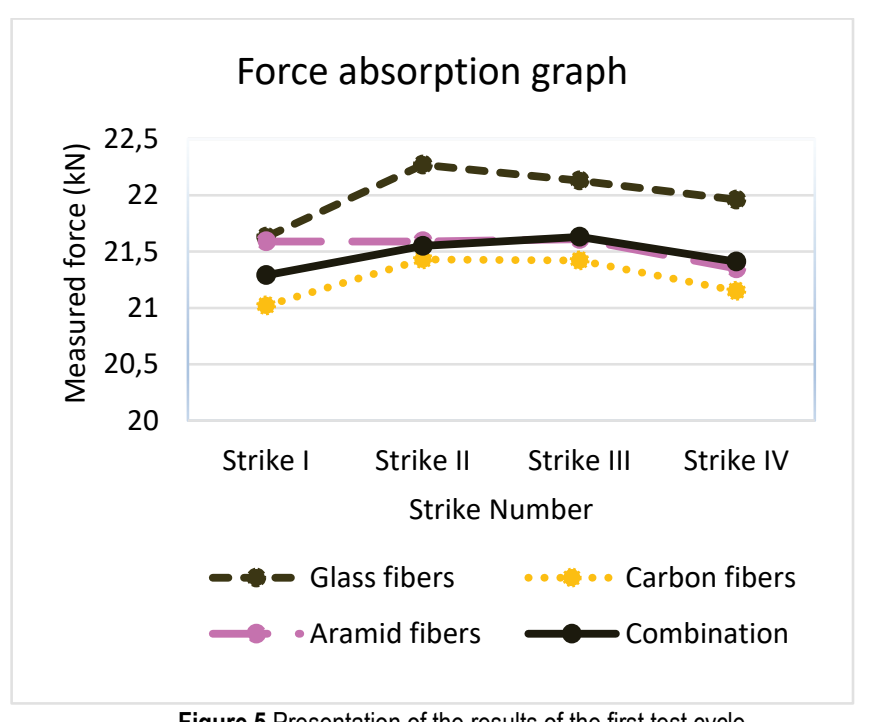

Figure 5 Presentation of the results of the first test cycle

In the test of composite materials on impact, in which there is no foam as an additional material for force absorption, forces from $21.25 \mathrm{kN}$ to $22.47 \mathrm{kN}$ were recorded, which can be seen in Fig. 5.

The best results in terms of absorption are observed on carbon fibers, followed by carbon fibers in combination with 
aramid fibers, and aramid fibers while glass fibers showed the worst result and did not absorb force like other tested materials.

Tab. 2 shows the measured test values for the case when a $10 \mathrm{~mm}$ thick foam is placed under the composite tiles.

Table 2 Results for tiles with a $10 \mathrm{~mm}$ thick foam

\begin{tabular}{|c|c|c|c|c|c|}
\hline \multirow{2}{*}{ Sample } & \multirow{2}{*}{$\begin{array}{c}\text { The place } \\
\text { of impact }\end{array}$} & $\begin{array}{c}\text { Glass } \\
\text { fibers }\end{array}$ & $\begin{array}{c}\text { Carbon } \\
\text { fiber }\end{array}$ & $\begin{array}{c}\text { Aramid } \\
\text { fibers }\end{array}$ & $\begin{array}{c}\text { A combination } \\
\text { of carbon and } \\
\text { aramid fibers }\end{array}$ \\
\hline \multirow{2}{*}{$\begin{array}{c}1^{\text {st }} \\
\text { sample }\end{array}$} & I & 10.71 & 7.67 & 12.5 & 9.56 \\
\hline \multirow{2}{*}{$\begin{array}{c}2^{\text {nd }} \\
\text { sample }\end{array}$} & II & 13.59 & 6.48 & 11.4 & 9.5 \\
\cline { 2 - 6 } & IV & 11.23 & 6.07 & 11.68 & 7.05 \\
\hline \multicolumn{2}{|c|}{ Arithmetic mean $(\bar{X})$} & 11.91 & 6.79 & 12.25 & 9.98 \\
\hline
\end{tabular}

In this test cycle, the largest differences between the results between different materials were observed, which is best seen in the deviation of the values of the forces obtained as a result $\left(F_{\min }=5.5 \mathrm{kN}, F_{\max }=13.5 \mathrm{kN}\right)$. Fig. 6 shows the deviations of the results between the different materials for each individual test.

The best results were again achieved by carbon fibers, followed by a combination of aramid and carbon fibers, aramid fibers and glass fibers.

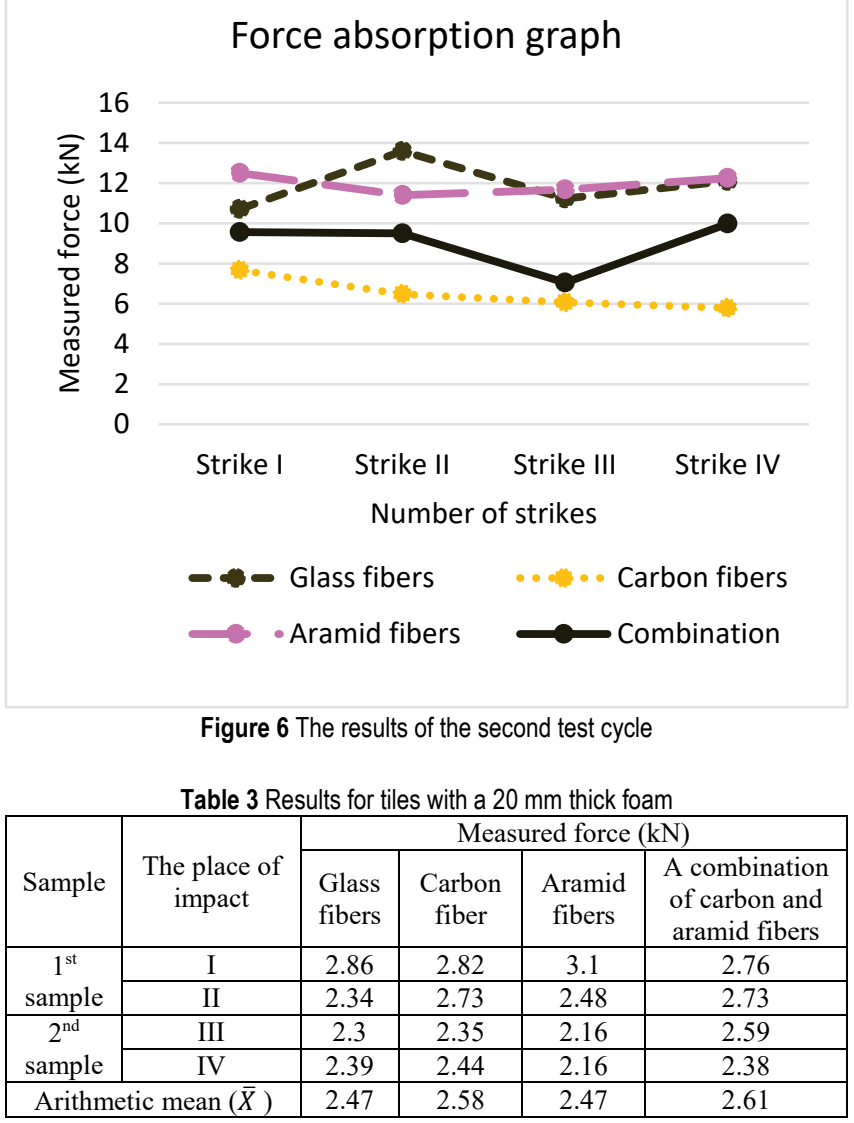

The results of the last test cycle are shown in Tab. 3 and Fig. 7. The last cycle, in which there was a foam $20 \mathrm{~mm}$ thick under the tiles of composite materials, showed results that are almost the same for all materials and do not deviate between different materials. This occurs due to the thicker foam that absorbs most of the energy.

In Fig. 7, we see how similar the results are regardless of the type of material.

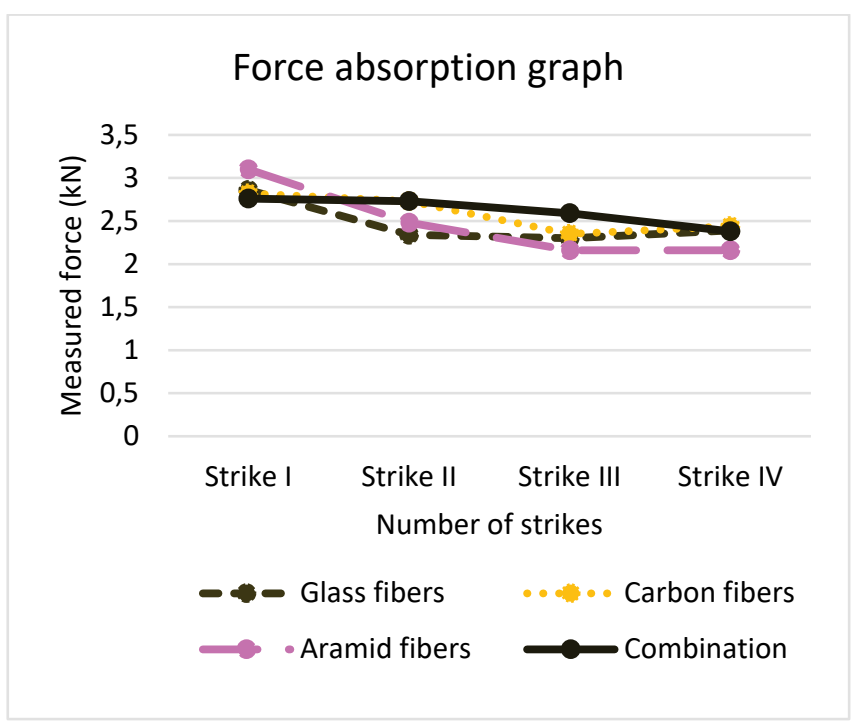

Figure 7 Presentation of the results of the third test cycle

\subsection{Comparison of Results}

The test results showed that the thickness of the foam under the composite material affects the value of the force loaded by the sensor. The thicker the foam the more energy it absorbs.

Through three test cycles, it was concluded that the most energy was absorbed by carbon fiber materials as seen in the first cycle results, where there was no PE foam, and especially in the second cycle results where there was a 10 $\mathrm{mm}$ thick foam under the tile. The results of the second cycle show the largest discrepancies between the results of individual materials and it can be concluded that carbon fiber is the most appropriate choice when choosing materials for making a protective helmet because it absorbed the impact force, which served in the final decision.

The combination of aramid and carbon fibers had slightly worse results, however if the helmet needs to have some characteristics (toughness, wear resistance) that aramid fibers can provide, the choice of combination of carbon and aramid fibers may be better than choosing the carbon fibers themselves to make the helmet.

Aramid fibers and glass fibers absorbed the impact force less, so the results for these materials were worse.

By comparing the strength of the material and the amount of energy absorbed, the tests confirmed the findings on the relationship between strength and energy absorption. The higher the strength of the material, the greater the absorption.

\section{CONCLUSION}

Through examination of the impact absorption of composite materials, it was concluded that the materials that 
best absorb the force are carbon fibers. For this reason, it was decided to use carbon fiber to make a multifunctional protective helmet due to the force absorption ability and high strength (3000-5000 MPa), which guarantees maximum user safety.

It was concluded that further research of composite materials is possible and necessary using other criteria such as; price, appearance, comfort, reliability, etc.

\section{REFERENCES}

[1] Šercer, M. (2019). Proizvodnja kompozitnih tvorevina, Zagreb, Croatia, Faculty of Mechanical Engineering and Naval Architecture. (in Croatian)

[2] Smojver, I. (2007). Mehanika kompozitnih materijala, Zagreb, Croatia, Faculty of Mechanical Engineering and Naval Architecture. (in Croatian)

[3] Šimić, V. (2002). Otpornost materijala I (2nd edition), Zagreb, Croatia, Školska knjiga. (in Croatian)

[4] https://www.sestan-busch.hr/_(2021) Prelog, Croatia.

[5] Schaeffler. (2014). Technical guide, Nurnberg, Germany.

[6] Liu, P. S. \& Chen, G. F. (2014). Porous materials - Processing and Applications. Butterworth-Heinemann, Oxford.

[7] Wardle, M. W. (2000). Comprehensive composite materials. Germany.

\section{Author's contacts:}

Božo Bujanić, M.Sc. Ing. mech.

Sestan-Busch d.0.0.

Industrijska zona 3 ,

40323 Prelog, Croatia

E-mail: bozo.bujanic@fsb.hr

Matija Košak, M.Sc. Ing. mech.

(Corresponding author)

Sestan-Busch d.o.o.

Industrijska zona 3 ,

40323 Prelog, Croatia

E-mail: kosak95@gmail.com 